\title{
Redesigning professional development: reconceptualising teaching using social learning technologies
}

\author{
Thomas Cochrane ${ }^{a *}$ and Vickel Narayan ${ }^{\mathrm{b}}$ \\ ${ }^{a}$ Centre for Learning and Teaching, AUT University, Auckland, New Zealand; ${ }^{b}$ Te Puna Ako, \\ Unitec, Auckland, New Zealand
}

(Received 29 July 2012; final version received 7 April 2013)

\begin{abstract}
This article evaluates the use of a community of practice model for redesigning a lecturer professional development course investigating the impact of mobile web 2.0 technologies in higher education. The results show a significant change in lecturer conceptions of pedagogy were achieved by this approach. Drawing on our experience of two iterations of implementing the new course model we propose a mobile social media framework for enabling pedagogical transformation as part of lecturer professional development.
\end{abstract}

Keywords: communities of practice; Web 2.0; pedagogy; heutagogy; teaching and learning

\section{Introduction}

The researchers developed the social learning technologies (SLT) course as an experiential learning environment for its participants, and it was informed by a graduate-level critique and reflection upon emergent learning theory. The goals were to provide participants with a model and experience of both a community of practice (COP) and enabling mobile web 2.0 tools that they could then continue to develop within their own teaching and learning contexts after completion of the course. This was underpinned by a rigorous investigation of social learning theories and frameworks throughout the course and by scaffolding the experiential learning via the establishment of the course as a supportive COP. In particular, we used the concept of heutagogy (Hase and Kenyon 2000) as a framework to measure participants' progression along the pedagogy-andragogy-heutagogy (PAH) continuum (Luckin et al. 2010) from teacher directed to student directed. This represented a significant reconceptualisation of the role of the teacher and students in learning, as described by Brown, Metz, and Campione (1996).

In this model, the teacher and pupils agree on the areas and themes for research within an overall context. Students act as researchers on one of these themes or sub-themes and in so doing become the community experts on that theme. They are then in a position to teach the others in the classroom and thus contribute to the creation of common knowledge and understanding. In order to carry out these tasks, the learners develop a

*Corresponding author. Email: thomas.cochrane@aut.ac.nz 


\section{T. Cochrane and V. Narayan}

language that becomes increasingly subject specific and academic as they learn and disseminate. (p. 161)

While there is a growing body of research around the concept of heutagogy in education (Blaschke 2012), there are few examples in the literature of heutagogy in practice, and even fewer examples of it being used as an explicit framework for lecturer professional development. The authors redesigned the SLT course around a social constructivist pedagogy that leveraged several emergent learning frameworks. Creating the foundation and circumstances for pedagogical transformation was the goal. This transformation is aptly described by a group of educational technology researchers calling themselves the learner-generated context group (Luckin et al., 2010) via the concept of bridging the PAH continuum. Luckin et al. (2010) argue that heutagogy (student-directed learning) need not be the domain of postgraduate research students only, and propose the concept of learner-generated contexts as a framework to help achieve this. Originally proposed by Hase and Kenyon (2000), the concept of heutagogy has been extended by Garnett (2010), who describes the process of reconceptionalising pedagogy in three steps following the PAH continuum: moving from pedagogy (teacher-directed learning) to andragogy (studentcentred, student-generated content) and finally towards heutagogy (student-directed learning).

(1) The ability to understand how to use their subject for teaching is an effective pedagogy.

(2) To understand how to manage the learning environment they are working in and treat each learner as an individual is the andragogy of learning relationships.

(3) Then, having learnt how to manage the learning process related to their subject, they then turned over their control to their learners, enabling the heutagogy of creativity to kick in (Garnett 2010).

We argue that heutagogy does not imply an abdication of the responsibility of a teacher, but involves a reconceptualisation of the roles of the teacher and learner. Achieving this reconception takes significant time, involving sustained engagement, support, and critical reflection. The critical need for transforming pedagogy via sustained collaborative research based on sound design principles has been highlighted by other educational technology researchers, such as Reeves (Amiel and Reeves 2008; Reeves, Herrington, and Oliver 2005) and Laurillard (2012).

\section{Research objectives}

The objectives of the research around the development and implementation of the new SLT course were to evaluate the effectiveness of a course modelled as a COP of lecturers as a way of fast tracking the participants' journey of reflective practice to help them become expert teachers who move from teacher-directed pedagogy to facilitators of student-determined learning, or heutagogy (Hase and Kenyon 2000). Facilitating an experience similar to Garnett's (2010) conception of "heutagogy and the craft of teaching," mobile web 2.0 tools are used as catalysts for pedagogical transformation (Kukulska-Hulme 2010) within the SLT COP. 


\section{Development of the SLT course}

The Graduate Diploma of Higher Education (GDHE) is one of the institution's primary methods of lecturer professional development. The GDHE is a 120-credit graduate qualification made up of a selection of core courses and elective courses, including the 15-credit learning technologies elective course. However, the learning technologies course of the GDHE had become dated and antiquated. The authors were tasked with redeveloping this course and bringing it into alignment with the institution's new elearning strategy.

\section{The context}

The GDHE is based in New Zealand's largest polytechnic, and the institution is in the process of differentiating itself from New Zealand's eight universities with the rollout of a distinctive pedagogical approach termed the "Living Curriculum," which is exemplified in the institution's new elearning strategy (see Cochrane et al. 2012).

\section{The COP model for professional development}

A COP model was developed (Cochrane 2007; Cochrane and Kligyte 2007) to support the implementation of over 30 mlearning projects managed and implemented in partnership with a variety of lecturers by the authors between 2006 and 2010, and it has become a core element of the institution's new elearning strategy (Cochrane 2010). The 2006-2010 research was interested in bringing about sustainable and transferable pedagogical change that would benefit lecturers and students, transforming pedagogy from a face-to-face classroom-based instructivist paradigm to a context bridging a social constructivist paradigm. Mobile web 2.0 tools were used as a catalyst for this pedagogical change. To achieve this goal, the second problem was creating an implementation approach that did not rely upon (or that never went beyond) already techno-savvy ("geek") lecturers, but was capable of supporting and scaffolding the average lecturer to help him or her become confident with integrating innovative technologies into the curriculum. Rather than relying upon a series of workshops, the sustained engagement of a COP was found to achieve significant ontological shifts (Chi and Hausmann 2003) or reconceptions for both lecturers' conceptions of teaching and students' conceptions of what it means to be a learner.

\section{Research methodology}

A participatory action research methodology (Swantz 2008; Wadsworth 1998) was used for evaluating the impact of the redesigned SLT course, which was embedded within the rollout of the institution's new elearning strategy and developed with strategic input from the authors of this article. Thus, the researchers were interested in facilitating positive change within their institution as a result of the redesign and implementation of the new SLT course. This change specifically involved facilitating transformational journeys for the participants by initiating them into reflective practice that would move them from a focus on teacher-directed pedagogy to facilitating student-directed heutagogy (Blaschke 2012; Garnett 2010; Hase and Kenyon 2000; Luckin et al. 2010). The research participants included all of the members of the COP who were involved with the SLT course: the researchers as the 


\section{T. Cochrane and V. Narayan}

lecturers of the SLT course and the course students. The researchers were the main collators of the research data, while feedback from the students helped inform the continuing refinement and development of the SLT course and included student negotiation of assessment criteria based around authentic student-generated projects, with peer collaboration and peer marking contributing to students' summative assessment grades. All SLT students signed ethics consent forms and an acceptableuse policy statement relating to the use of the mobile web 2.0 tools throughout the course. The 2010 SLT class began with eight enrolling students, with two students withdrawing in the first week of the course due to time constraints, leaving a small but committed class of six students and two facilitating lecturers. The second iteration of the SLT course ran in 2011, involving 13 enrolling and 10 completing lecturers as students and the two researchers as the SLT course lecturers. The course participants were expected to have a wifi-capable laptop for use during the course. Students who did not have access to a laptop were supplied with a netbook for use throughout the course. Additionally, all of the course students were supplied with a smartphone for use during the course (an iPhone 4 in 2010 and an HTC Desire Android smartphone in 2011), allowing them to experience the affordances of mobile web 2.0. The introductory session of the course established the core collaboration tools used to enable the COP to operate beyond the face-to-face sessions, including Twitter (including a course hashtag), personal blogs, a group wiki page, Gmail and associated Google Apps, and a course Moodle hub, where students added their web 2.0 contact details to their Moodle profiles. The Moodle LMS (Learning Management System) was therefore used as a scaffold while students established their own PLE (Personal Learning Environment) consisting of a mashup of web 2.0 tools or "pedagogy 2.0" (McLoughlin and Lee 2010).

\section{Data collection and triangulation}

Data collection consisted of the following:

(1) Beginning-of-course surveys of lecturers and students to establish current practice, expertise, and experience. A copy of the survey form can be found at http://tinyurl.com/bv7wda9.

(2) Postcourse surveys (http://tinyurl.com/cmd2hc3) and focus group surveys (http://tinyurl.com/cjcr93v), to measure the impact of the mobile web 2.0 environment and identify emergent themes.

(3) Lecturer and student reflections via their own blogs and eportfolios throughout the course. Students were required to make at least 10 significant blog posts during the course as their main assessment. These blog posts were collated via RSS (rich site summary) feeds in Google Reader and shared with the participants.

The research used the technologies that were an integral part of the redesigned course assessment, such as participant blog posts, peer blog comments, Google Forms for assessment marking rubrics and student feedback on the course, and student VODCast reflections to capture data on the progression and impact of mobile web 2.0 on the participants' learning experience. In analysing the qualitative data, the two researchers read through all of the student blog posts and peer comments, viewed the student video reflections, and interviewed every student at the end of the course. 
These multiple qualitative data sources allowed triangulated identification of emergent themes, which are explored in this article's results and discussion.

\section{Communities of practice}

COP is a social learning theory. The concepts were proposed by Lave and Wenger (1991) while studying the apprenticeship model of learning. Wenger (1998) later further developed the concepts, and then simplified the concepts for wider contexts: "Communities of practice are formed by people who engage in a process of collective learning in a shared domain of human endeavor" (Wenger 2005). Though not originally intended as a pedagogical strategy or teaching technique, but rather as an analytical viewpoint on learning (Lave and Wenger 1991), the concepts of COP have found popularity within educational contexts. The main differences between traditional teacher-directed (didactic) educational environments and COP are an emphasis on inventiveness with a continual evolution of the ideas and direction of the community (Brown 2006), a lack of hierarchy (Head and Dakers 2005; Langelier 2005), and teachers taking on the role of expert mentors (Herrington et al. 2006) rather than deliverers of content.

The SLT course was designed as an intentional COP. Wenger's (2006) definition of COPs "allows for, but does not assume, intentionality" (Wenger 2006). While COPs often form organically and spontaneously, they can also be created intentionally and cultivated for specific purposes. Intentional COPs share the same characteristics as organic COPs, but have at their core a plan.

One of the key concepts developed out of COPs has been the importance of "technology stewards" (Wenger, White, and Smith 2009; Wenger et al. 2005) as members of COPs who guide the use of technologies supporting the COP. Within the context of the SLT course, the course lecturers took on the role of technology stewards, attempting to model the pedagogical use of mobile web 2.0 as part of a collaborative partnership with the course students.

\section{Social learning theory and frameworks}

The SLT course was explicitly founded upon social constructivist learning theory (Vygotsky 1978) and focussed on students investigating related pedagogical theory and frameworks and the appropriation of web 2.0 tools to implement these theories and frameworks within their own pedagogical practice. These included both established and emerging theories and frameworks such as communities of practice (Lave and Wenger 1991), the conversational framework (Laurillard 2001), learnergenerated content and learner-generated contexts (Luckin et al. 2010), authentic learning (Herrington and Herrington 2007; Herrington and Oliver 2000), connectivism (Siemens 2004), and activity theory (Engestrom 1987).

Links were provided to educational research organisations that publish regular reports and RSS feeds to new resources, thus keeping the course "readings" up to date rather than relying upon rapidly aging set texts. These included the following:

- Educause, 7 Things You Should Know About Series (http://www.educause. edu/7Things)

- JISC reports (http://www.jisc.ac.uk/publications.aspx)

- New Consortium reports (http://www.nmc.org/publications) 


\section{T. Cochrane and V. Narayan}

- Educause Resources (http://www.educause.edu/resources)

- Becta (http://research.becta.org.uk) - now defunct.

\section{Redesigning the GDHE SLT course}

The redesign of the GDHE learning technologies course into the new SLT course was a collaborative process by the two authors throughout 2009. The final course was approved in late 2009 and ran for the first time in the second semester of 2010 with the two authors as the course lecturers.

\section{Course outline: 2009 versus 2010}

The original learning technologies course centred on the course participants creating a resource for their students to use (i.e. teacher-generated content). The redesigned SLT course focussed on modelling the use of mobile web 2.0 tools as a catalyst for pedagogical transformation, leading to the participants developing their own theory and experience-informed teaching and learning framework. This framework was to establish links between new and emerging learning technologies and social learning theories, and then became the basis from which they developed student-directed learning activities for their context (i.e. enabling student-generated content and student-generated learning contexts). Table 1 outlines the key differences in the redesign of the SLT course with reference to the PAH continuum (Luckin et al. 2010).

The SLT course ran over the period of a semester, with six 3-hour-long face-toface sessions. Figure 1 illustrates the structure of the course, within the framework of an intentional COP.

There were two assessments for the course, and these were designed to provide students with an authentic experience of active participation within a COP exploring social constructivist pedagogies enabled by mobile web 2.0 tools. All assessment materials were to be posted to students' blogs. Assessment 1 required students to design a personal teaching framework that establishes links between new and emerging learning technologies and social learning theories. The first assessment $(50 \%)$ was marked according to six criteria: reflection, argument, referencing, associations with the student's current teaching practice, use of digital media and collaboration with peers. Assessment $2(50 \%)$ required students to use their framework to design and facilitate an appropriate student-centred learning activity, present it to the class and evaluate its effectiveness. The second assessment was marked by their peers and the facilitators, using a rubric via Google Forms that rated five criteria and also provided comments as feedback. The five criteria for assessment 2 evaluated the following: the justification of their framework, the presentation of an explanatory concept map, an outline of the design of their activity, the use of their

Table 1. The PAH continuum and the SLT course before and after the redesign.

\begin{tabular}{llll}
\hline & \multicolumn{1}{c}{ Pedagogy } & \multicolumn{1}{c}{ Andragogy } & \multicolumn{1}{c}{ Heutagogy } \\
\hline Locus of control & Teacher & Learner & Learner \\
Cognition level & Cognitive & Metacognitive & Epistemic \\
Knowledge production context & Subject understanding & Process negotiation & Context shaping \\
GDHE course alignment & Prior LT course & & New SLT course \\
\hline
\end{tabular}

Modified from Luckin et al. 2010, p. 78. 


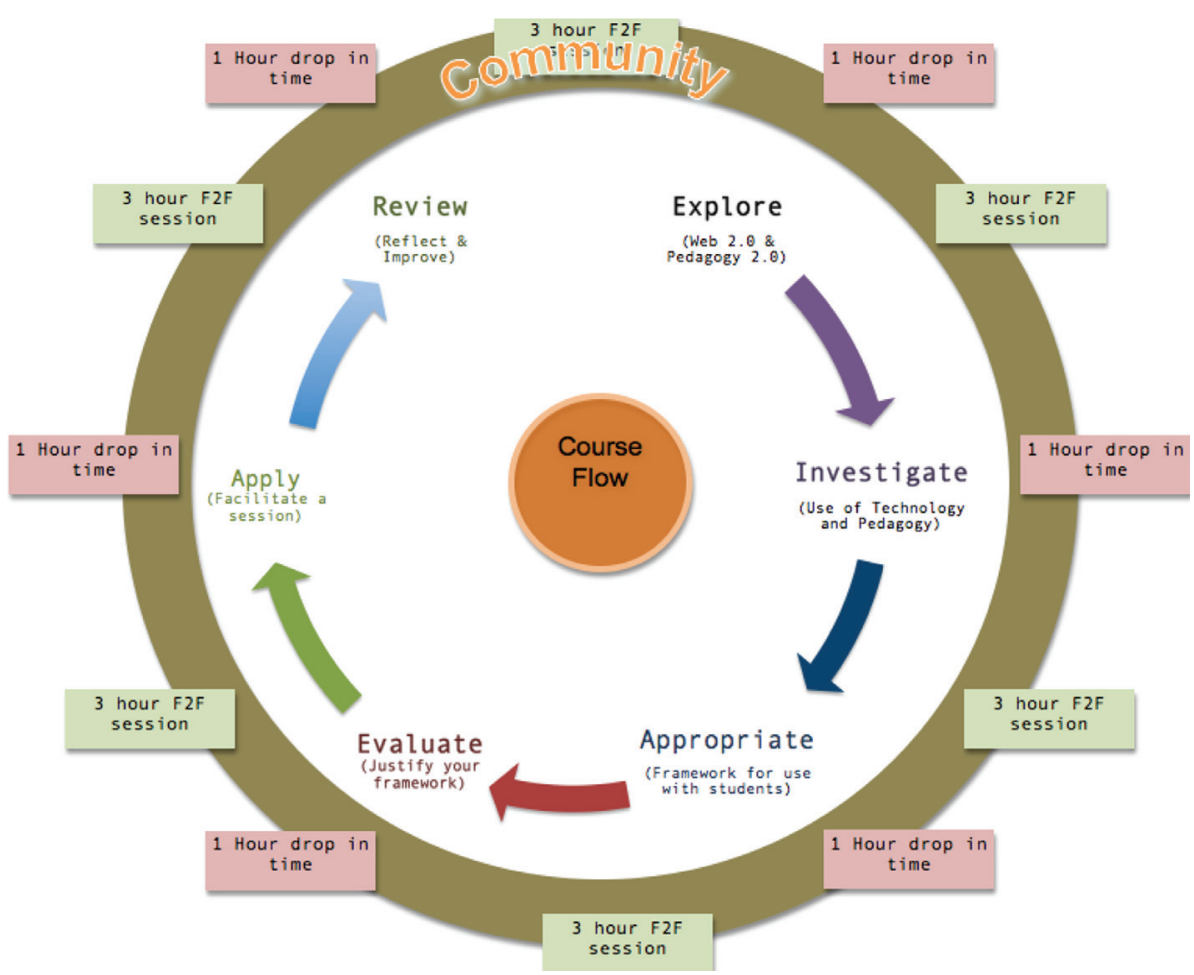

Figure 1. Outline of the SLT course.

framework and web 2.0 tools in the facilitation of their presentation, and the quality of their presentation.

\section{Results}

This section discusses the findings of the research into the impact on the professional development of the participants resulting from the design of the SLT course around an experiential COP. Thus, we provide a selection of examples of participants' journeys towards heutagogy. A summary of the SLT course results is provided in Table 2.

Table 2. Comparison of 2010 and 2011 course results.

\begin{tabular}{lll}
\hline & 2010 & 2011 \\
\hline Number of students & 6 & 10 \\
Peripherally participating students & 1 & 1 \\
Assignment1 average mark & $81.6 \%$ & $78.4 \%$ \\
Assignment1 lowest mark & $50 \%$ & $50 \%$ \\
Assignment1 highest mark & $96 \%$ & $100 \%$ \\
Assignment2 average mark & $72.1 \%$ & $82.6 \%$ \\
Assignment2 lowest mark & $60.6 \%$ & $63.6 \%$ \\
Assignment2 highest mark & $82.5 \%$ & $94 \%$ \\
Pass rate & $100 \%$ & $100 \%$ \\
Initial course pullouts & 2 & 3 \\
\hline
\end{tabular}




\section{T. Cochrane and V. Narayan}

\section{0}

The bulk of the participants in the first iteration of the course in 2010 were from the vocational training departments, including boat building, automotive, carpentry and the electrical trades. The students were skilled tradesmen but not necessarily skilled teachers, and most had limited experience with integrating technology into their teaching practice, but they were keen to explore the potential beneficial impact for their students. The participants' ages ranged from 29 to 59, with an initial enrolling cohort of 7 male and 2 female participants.

\section{Student surveys}

The beginning of the course student surveys provided data on students' previous technology usage experience.

Figure 2 compares the responses of the 2010 and 2011 SLT students to the precourse survey. Figure 2 indicates that while the SLT participants all had computer and Internet access, and the majority owned a mobile phone, most of their web experience had previously been as consumers of information and media rather than as producers. There was minimal use of interactive web 2.0 technologies prior to the course, with those who were already engaging in web 2.0 having previously worked with the authors on projects; in particular, half of the 2010 students had already established the use of blogging and photo sharing via Flickr.

The students' responses in their final reflective blog posts and the end-of-course survey were overwhelmingly positive about the impact of the course on their conceptions of pedagogy and mobile web 2.0. These are collated in a word cloud in Figure 3.

The final blog post reflections illustrate a focus on the design of student learning activities, rather than a focus on the delivery of course content; this was a significant

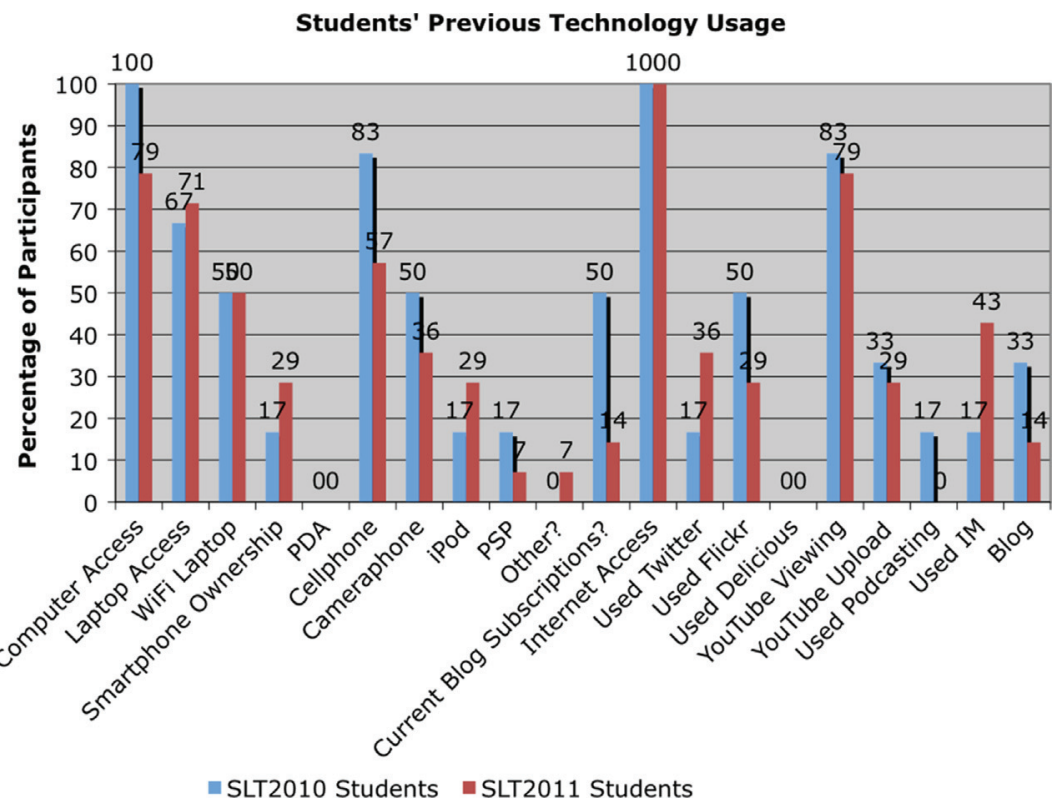

Figure 2. SLT students' previous technology experience. 


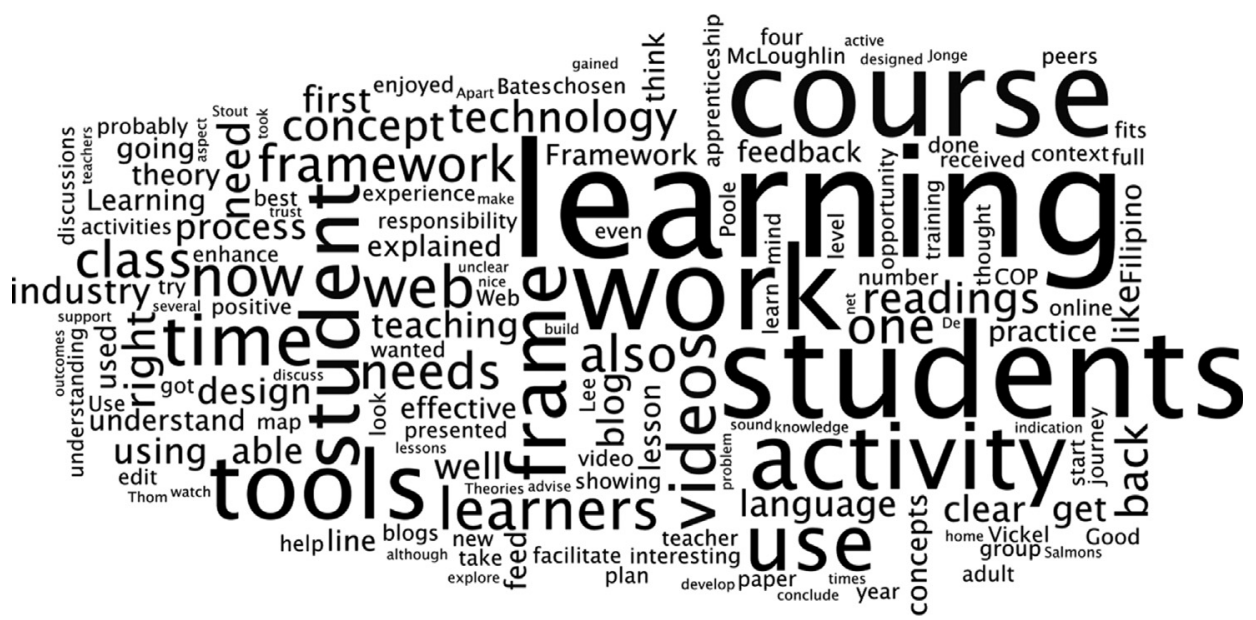

Figure 3. 2010 Student course reflections.

conceptual shift in the participants; understanding of their role as educators. Figure 4 is a collation of student feedback on their own experiences as students in the SLT course.

Students also recorded short video reflections throughout the course, and these have been collated in a YouTube playlist at http://www.youtube.com/playlist?list= PL2-TasqEeWBtfnXk1tHM7EDMDdqJhM5UC.

\section{Transformational journeys}

The key goal of the course is for the lecturers to model the use of mobile web 2.0 tools embedded within an intentional COP composed of the course lecturers and the course students. The course students were then guided to apply their experience to

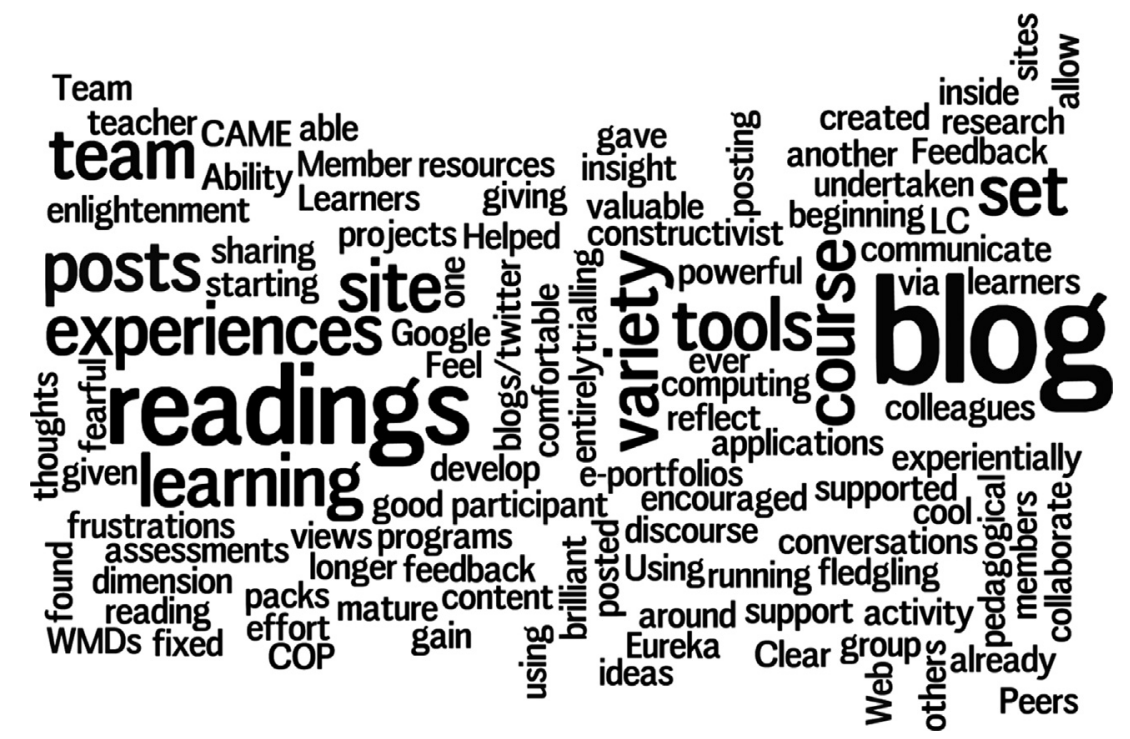

Figure 4. 2010 Student course feedback. 


\section{T. Cochrane and V. Narayan}

create a personal framework for authentic experiential learning within their own teaching contexts. This represented a significant process of reconceptualising the participants' notions of identity and agency within teaching (i.e. an ontological shift). For many lecturers, this will require an "ontological shift" in their understanding of what it means to teach, and it can represent a fundamental challenge to the lecturer's understanding of self within the context of the nature of teaching and learning. An "ontological shift" is "the re-assignment or re-categorizing of an instance from one ontological category to another" (Chi and Hausmann 2003), or, simply put, a reconceptualisation. This shift involves a reconceptualisation of lecturers' understanding of teaching and learning from their prior experience to understandings built upon the foundation of learning theory such as social constructivism. This ontological shift can take significant time as lecturers reconceptualise and develop new and appropriate forms of assessment, collaboration and communication strategies. For several of the course students, the course facilitated an ontological shift from understanding their role as a tradesperson to reconceptualising their role as a teacher. Examples of the impact of the SLT course on participating students are discussed in the following sections.

\section{Boat building: lecturer 1}

This participant became a key peer mentor and driver for the group. He helped establish a real sense of community, encouraged the group to try to contextualise their learning and modelled collaborative discussion and critique using a range of technologies. For example, he initially experimented with creating personal reflective VODCasts, and then extended the concept to establish Skype video call discussions between the SLT students, screen-captured these and shared them on YouTube as examples of critical reflection upon the theoretical pedagogical frameworks (http:// www.youtube.com/watch? $\mathrm{v}=$ BPLYQIRSVhU).

The social collaboration built into the SLT course was very important for the participant's transformational journey.

The experience of the SLT course impacted this lecturer's own teaching practice by enabling him to form a theoretical foundation for his approach to teaching based on social constructivism that he explicitly implemented with his students in 2011 (http://www.youtube.com/watch?v=qoJEggkvygw).

\section{Carpentry: lecturer 1}

This participant synthesised his experience as a student in the SLT course and his own teaching practice to create innovative ideas for use with his own students. His goal in participating in the SLT course was to explore how to more closely link the theory and practical components of his carpentry course by getting his students involved in capturing, sharing and critiquing their practical onsite work via short videos recorded on their smart phones and uploaded to their blogs. He enjoyed the experience of the course, and by the end of the course, this participant also demonstrated a new level of critical pedagogical reflection.

The experience of the SLT course impacted this lecturer's own teaching practice in 2011 by enabling him to conceptualise ways of integrating mobile web 2.0 tools into the context of bridging the theory and practice of building on the building site with 
his students. This led to the design and building of a portable "eShed" for theory lessons on site (http://www.youtube.com/watch?v=-tEDxHcV-4w).

\section{Boat building: lecturer 2}

This participant began the SLT course with the least previous experience of computing and web 2.0 of all of the 2010 participants. Initially, he was dubious of the benefit or applicability of mobile web 2.0 to his teaching context. However, during the process of investigative reading around theoretical frameworks for educational technology, he experienced a "eureka" moment: a dawning of how the combination of reading social constructivist theory, his SLT experience, and his previous teaching experience aligned to create a deeper understanding of teaching and learning. Following this experience, this participant became an educational technology evangelist, to the point of buying his own iPad and iPhone, and presenting his transformational journey using his brand-new iPad at a subsequent mini-symposium organised by the researchers (http://www.youtube.com/watch? $\mathrm{v}=$ zGEquKzzMyU\&feature=feedf). The experience of the SLT course impacted this lecturer's own teaching practice by providing him with a foundation for conceptualising how his own students could utilise iPod Touches to record and document their learning via blog-based eportfolios in 2011.

\section{1}

The students enrolling in the 2011 SLT course were from a wider background than the 2010 student cohort, with several students from private training establishments enrolling alongside lecturers from the institution. The 2011 students did not necessarily have an understanding of different pedagogies or have any knowledge of how to use the core Web 2.0 tools used in the course. This was also apparent in the 2010 iteration, where the students were mostly from the trade faculty and were hired as teachers due to their knowledge of the field (e.g. boat building or construction) rather than their teaching experience. As a result, the students felt a bit thrown in the deep end with the new learning experience represented by the SLT course and the embedded use of mobile web 2.0 tools. Some students chose not to engage with the tools and the wider class until they had built their own confidence through lurking and peripheral participation. A common thread observed in the course by the facilitators was the constant debate from the students on managing their online identity (private versus public) and their initial lack of confidence to actively engage online.

To remedy these issues, the first two sessions in the 2011 iteration were spent with students discussing issues and concerns regarding "living a life in a digital world" and introducing the fundamentals of teaching and learning, for example Bloom's taxonomy. The core tools for use in SLT (WordPress, Twitter and mobile devices) were also introduced at this stage. Figure 5 outlines the redesign that focussed on preparing and scaffolding the students for the journey in the 2011 SLT course. This gave the students time to discuss and agree on some etiquette for use in the course with the digital tools. This also allowed them to overcome any initial barriers in discussions with each other because the issues and concerns were shared by most students. The redesigned 2011 version of the SLT course outline was made viewable on Google Docs. 


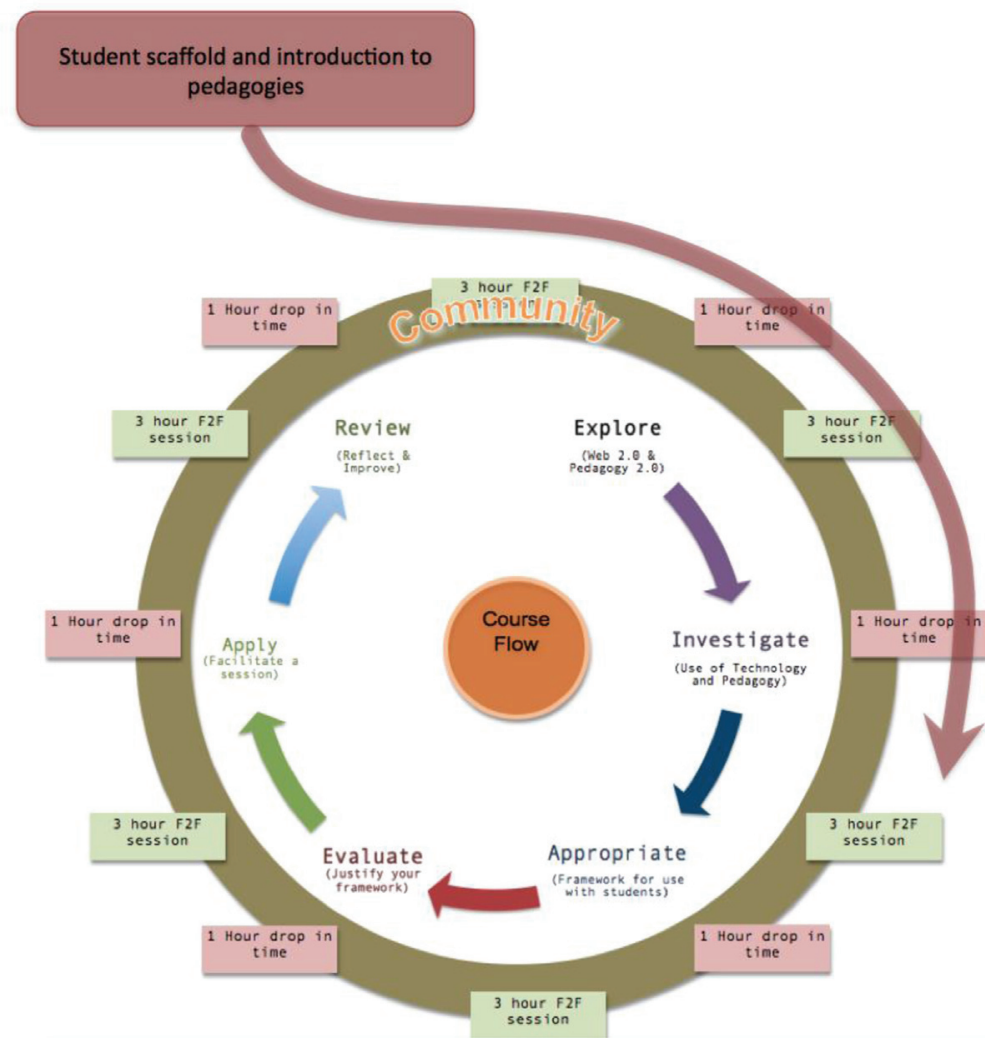

Figure 5. Redesigned SLT course for 2011 iteration.

The students' responses in their final reflective blog posts and the end-of-course survey were again overwhelmingly positive about the impact of the course on their conceptions of pedagogy and mobile web 2.0. These are collated in a word cloud in Figures 6 and 7 .

2011 students' video reflections have been collated in a YouTube playlist at http:// www.youtube.com/playlist?list=PL98A16C35D62D3CDA.

\section{Hairdressing tutor: 2011}

This participant came from a private training institution that provided a highly instructional classroom-based approach to teaching. This student quickly appropriated the concepts of Laurillard's conversational framework and Vygotsy's "zone of proximal development," and readily explored a wide range of social media tools to enable a conversational model in teaching and learning guided by an expert teacher. While initially somewhat overwhelmed by the breadth of mobile social media tools available, she critically evaluated a selection of social media tools in light of her two chosen learning frameworks. She expressed her appropriation of these frameworks and tools in a reflective blog post:

These frameworks I believe work well together, and especially at a higher education level, adult learners do not expect to sit in a room and be lectured to. They want to be taken seriously and want to know that their past knowledge and education is relevant and 


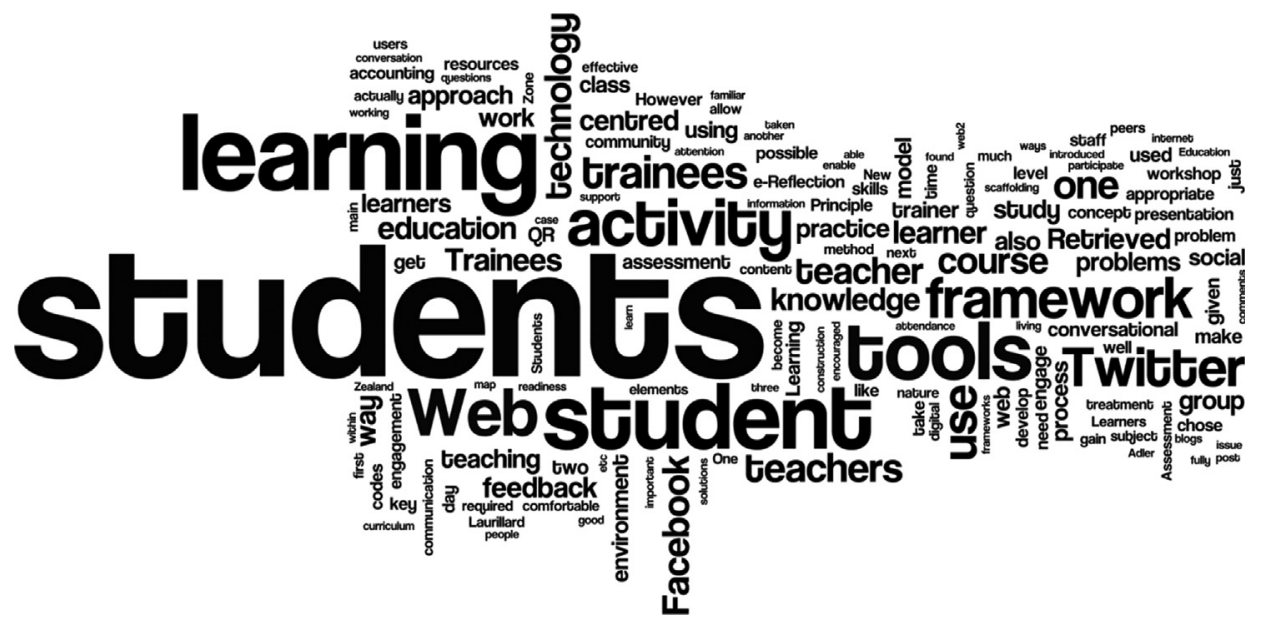

Figure 6. 2011 Student final reflections.

\begin{abstract}
important to the next step they have taken. Web 2.0 tools are also beneficial in the adult teaching and learning environment as they allow for the learner to take on the task at times and places that suit them, rather being stuck in a classroom. These tools allow for flexibility within the classroom and respect from the students in them knowing that they are doing all they can for their own learning. (SLT student blog post, 2011)
\end{abstract}

\title{
Technical trainer: 2011
}

This participant came from a background of being a technical trainer in the air force, which imposed stringent security issues around the use of social media in education in this environment. This student quickly saw the potential of student-directed learning (heutagogy) to empower his own students and developed a framework for utilising a wiki as a hub for student-generated content. The student created an outline of a Jet Engine Fundamentals course using Google Sites at https://sites.google.com/

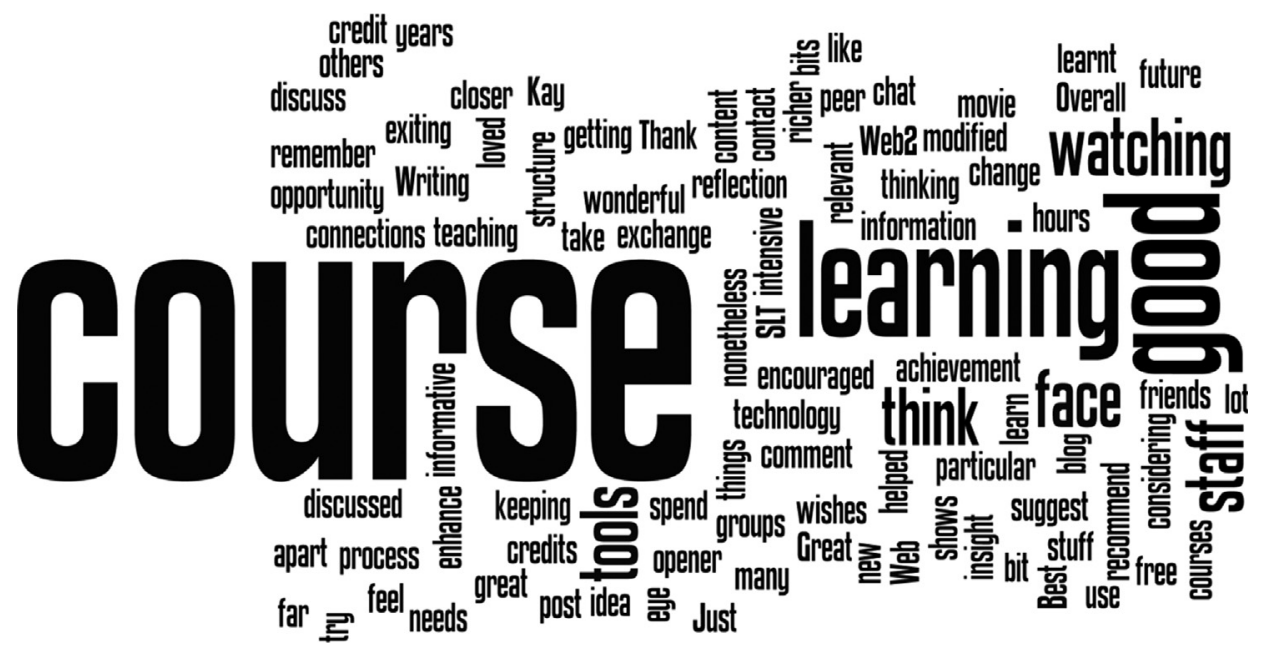

Figure 7. 2011 Student final feedback. 


\section{T. Cochrane and V. Narayan}

site/shortshout/home. Due to the limitations imposed by air force security restrictions on social media, the wiki course was created by the student as a theoretical example of the potential of aligning web 2.0 social media and student-directed learning, rather than actually implemented. The student expressed the impact of the SLT course on his conceptions of teaching and learning in a reflective blog post at the end of the course:

Well, what a journey! From digital immigrant to digital native in one go...

Over the past months I have come to realise that the full utilisation of Web 2.0 technologies requires the scaffolded introduction of the technology as well as the subject content. Modern learners, like my 'tech savvy' students, still expect to be taught in a fairly traditional manner and in order for Web 2.0 to flourish it must be introduced in a supported and managed manner. This course and its experiences, trials and tribulations has allowed me to get an insight into technologies that exist just around the corner (for the RNZAF) and may have converted me from a digital immigrant to a digitally naive. (SLT student blog post, 2011)

\section{Learning support lecturer: 2011}

This participant underwent a significant journey from holding a prior instructivist educational philosophy to engaging with the concepts of social constructivism by the end of the 2011 course. This was evidenced by several critical events during the course where the student struggled to come to grips with collaboration and open sharing of content via web 2.0. Coming from a highly cognitive approach to her own learning, this student printed and read all of the suggested readings and reports that formed the course's suggested resources before the course even began, and she even started on the assessments before the commencement of the course. Conveying the idea of a social constructivist approach to learning by forming a learning community with the other course students was incredibly difficult for her to initially comprehend as it did not align with her previous educational experiences. Her explorations of new pedagogical concepts tended to be highly theoretical, in-depth, and overly complicated, with a tendency to achieve by producing voluminous work and a reluctance to make her work public to limit plagiarism by the other course students. However, as the course progressed, this student gradually aligned the theory of the zone of proximal development and situated learning with her own learning experience in the SLT course, and she became a core member of the SLT 2011 COP. This was expressed in a reflective blog post:

This is challenging for me because I like to plan ahead, and traditional teaching practices often encourage the teacher to be in charge. But to make something belong to the community and reduce the traditional power relations, I think it has to be built more by the community itself. (SLT student blog post 2011)

\section{Discussion}

While the number of participants in the two SLT course iterations was small (although average for the GDHE courses in general), with a 2010 cohort of 6 students and 10 students in 2011, the results in terms of pedagogical transformation are indicative of those observed by the researchers throughout over 30 mlearning projects using the developed intentional COP support model between 2006 and 2010. 
The SLT course serves as an example of the impact of mobile web 2.0 integration supported by an intentional COP as an alternative approach to transformative professional development for lecturers.

This was achieved by the development of the SLT course as an intentional COP that supported the development of a mobile social media framework enabling ontological shifts along the PAH continuum, as outlined in Table 3.

\section{Sustained engagement leading to ontological shifts}

The SLT case study illustrates that creating sustained engagement around the integration of mobile web 2.0 tools supported by communities of practice can facilitate ontological shifts among the participants. Two key issues around reconceptualising teaching and learning that represented ontological shifts in the participants' understanding were identified:

(1) Shifting lecturers from pedagogy to heutagogy, and reconceptualising teaching as proposed by Luckin et al. (2010) and McLoughlin and Lee (2008)

(2) Shifting students beyond their previous experience, reconceptualising learning, and using the mobile web 2.0 tools to engage students via a focus on student-generated content and student-generated contexts.

There were certain elements of the SLT course that the participants found harder than others. For example, the participants took a while to get used to using correct referencing and bibliographic tools, particularly within the context of blogging. This was important to underpin the course experience with graduate-level critical thinking. Some students took a while to get into the swing of using Twitter for communicating, with several "lurking" until a momentum developed, and then they became quite engaged by using Twitter once a community had been established around its use in the course, effectively moving from legitimate peripheral participation to full participation in the core of the COP.

The "intentionality" of the SLT COP was embedded in the course design and assessment activities, with the authors purposely building the course as an authentic learning experience. In contrast to an organic COP, active participation in the course COP was mandated as an assessed activity. However, this intentional COP kickstarted the participants' experience of COP formation and has led to the organic development of continued COPs by the course graduates. As the majority of 2010 SLT students were located within the same faculty, these SLT graduates continued to build their own COP after the end of the SLT course, inviting their peers to join this COP. The 2010 graduates also took a keen interest in the 2011 iteration of the course, joining in Twitter conversations with the 2011 participants, offering links to resources and even technology support for the 2011 cohort, and effectively becoming brokers of their own transformational journeys.

\section{Participant feedback informing the 2011 implementation}

Feedback was gathered from a variety of sources from the 2010 participants, including analysis of participants' blog posts, a face-to-face debrief between each 
Table 3. A framework for using mobile social media to enable ontological shifts.

\begin{tabular}{|c|c|c|c|}
\hline & Pedagogy & Andragogy & Heutagogy \\
\hline Locus of control & Teacher & Learner & Learner \\
\hline $\begin{array}{l}\text { Course time } \\
\text { frame and goal }\end{array}$ & $\begin{array}{l}\text { Initial establishment of the course } \\
\text { project }\end{array}$ & $\begin{array}{l}\text { Early to midcourse: student appropriation } \\
\text { of mobile social media as applicable to their } \\
\text { chosen socioconstructivist pedagogies }\end{array}$ & $\begin{array}{l}\text { Middle to end of course: students apply their } \\
\text { learning to develop learning activities that } \\
\text { model active participation within an authentic } \\
\text { community of practice }\end{array}$ \\
\hline Cognition level & Cognitive & Metacognitive & Epistemic \\
\hline $\begin{array}{l}\text { Knowledge } \\
\text { production } \\
\text { context }\end{array}$ & $\begin{array}{l}\text { Subject understanding: lecturers } \\
\text { introduce and model the use of a } \\
\text { range of mobile social media tools to } \\
\text { support COP formation }\end{array}$ & $\begin{array}{l}\text { Process negotiation: students negotiate a } \\
\text { choice of mobile social media tools to } \\
\text { establish an eportfolio based on } \\
\text { user-generated content }\end{array}$ & $\begin{array}{l}\text { Context shaping: students create learning activities } \\
\text { that leverage user-generated content within the } \\
\text { context of their area of discipline interest. These } \\
\text { are then shared, curated, and peer-reviewed within } \\
\text { the COP }\end{array}$ \\
\hline $\begin{array}{l}\text { COP participa- } \\
\text { tion }\end{array}$ & $\begin{array}{l}\text { Initial induction into a supportive } \\
\text { learning community }\end{array}$ & $\begin{array}{l}\text { Enabling user-generated content and active } \\
\text { participation within a supportive learning } \\
\text { community }\end{array}$ & $\begin{array}{l}\text { Enabling collaboration across user-generated } \\
\text { contexts and active participation within a COP }\end{array}$ \\
\hline $\begin{array}{l}\text { Supporting } \\
\text { mobile social } \\
\text { media } \\
\text { affordances }\end{array}$ & $\begin{array}{l}\text { Establish a digital identity using } \\
\text { Wordpress, Twitter, and Google Plus }\end{array}$ & $\begin{array}{l}\text { Establish a personal learning environment } \\
\text { using a variety of mobile social media } \\
\text { content creation tools }\end{array}$ & $\begin{array}{l}\text { Curation and sharing of developed learning } \\
\text { activities using YouTube, Wikispaces, Storify, } \\
\text { Scoopit, and so on }\end{array}$ \\
\hline Ontological shift & $\begin{array}{l}\text { Reconceptualising mobile social } \\
\text { media: from a social to an } \\
\text { educational domain }\end{array}$ & Reconceptualising the role of the teacher & Reconceptualising the role of the learner \\
\hline
\end{tabular}
educational domain 
participant and the course lecturers at the end of the course, final student surveys, and feedback elicited by an independent course reviewer after the course had finished via email and personal phone call interviews with participants.

Feedback indicated that some participants initially felt a bit thrown in the deep end with the new learning experience represented by the SLT course and the embedded use of mobile web 2.0 tools. However, by the end of the course, feedback from the students indicated they were "no longer fearful" of trying new technologies. Some participants suggested adding extra scaffolding for the mobile web 2.0 tools via extra drop-in tutorials (these were offered during the course, but no one took up the offer). Bridging the other GDHE courses into the SLT course was also suggested. The integration of elements of the SLT course throughout the rest of the GDHE is one of the goals of the authors.

\section{Limitations}

As an assessed course, the researchers attempted to model an intentional COP as far as possible without the assessment becoming the core driver for participation. The SLT course was designed to provide students with an experience of social constructivist learning, underpinned by reflection on sound pedagogical theory, and enabled by mobile web 2.0 technologies. As such, we (as the "teachers") of the course attempted to model this approach in our facilitation of the course; for example, we used alternative web 2.0 tools for in-class presentations, including Prezi (http:// www.prezi.com); we used web 2.0 communication tools such as Twitter for remote and in-class brainstorming; and we modelled the pedagogical use of blogs and moblogging in our own practice. These helped the students conceptualise how to use these tools in their own practice. However, this generally required significant time and reflection by the students, for whom the "lights came on" near the end of the course.

We also allowed a certain amount of negotiation with the students around the course goals and assessment activities (as far as the redesigned course descriptor would allow) - allowing the COP that developed to be unique to the participants, who tended to find it a new experience; this was reflected in the different emphases of each iteration of the course in 2010 and 2011.

We have highlighted examples of the 2010 and 2011 SLT student journeys, illustrating significant conceptual shifts in their understandings of pedagogy and their roles as educators. Some students remained on the periphery of the SLT COP and simply did what was needed to pass the course (one student in each year - see Table 2); however, these were the minority, and they had to demonstrate a new understanding of pedagogical practice informed by current learning theory as this was embedded into the assessment. Thus, we argue that we had significant success in achieving ontological shifts in the participants because this was the explicit goal and was built into the design of the course.

\section{Conclusions}

The SLT course demonstrates the transformative impact of a COP model of lecturer professional development (Cochrane et al. 2012). The 2010 and 2011 course graduates have now become technology stewards within their own departments and institutions, effectively drawing in their peers from the periphery of the SLT COP 


\section{T. Cochrane and V. Narayan}

and forming spin-off COPs within their own departments and institutions. Thus, the SLT course has had a significant transformative impact not only on the participating students but also on the teaching and learning culture of their institutions. Scaffolding the integration of mobile and social technologies within the SLT COP involved a range of approaches, including modelling by technology stewards, peer mentoring, and the utilisation of flexible technologies beyond face-to-face contact. The selection of several student experiences illustrates the significant transformation achieved as a result of the authentic experience of a COP enabled by web 2.0 tools. From these experiences, we have proposed a mobile social media framework for pedagogical transformation that is scaffolded by a COP and utilises the unique affordances of mobile social media to act as a catalyst for reconceptualising teaching and learning from teacher-directed instruction towards student-directed heutagogy. This reifies previous theoretical explorations of heutagogy (e.g. Luckin et al. 2010) into a practical framework that can potentially be applied to other professional development contexts.

\section{References}

Amiel, T. \& Reeves, T. (2008) 'Design-based research and educational technology: rethinking technology and the research agenda', Educational Technology \& Society, vol. 11, pp. 29-40.

Blaschke, L. M. (2012) 'Heutagogy and lifelong learning: a review of heutagogical practice and self-determined learning', The International Review of Research in Open and Distance Learning, vol. 13, pp. 56-71.

Brown, J. S. (2006) 'New learning environments for the 21st century: exploring the edge', Change: The magazine of higher learning, vol. 38, no. 5, pp. 18-24.

Brown, A., Metz, K. \& Campione, J. (1996) 'Social interaction and individual understanding in a community of learners: the influence of Piaget and Vygotsky', in Piaget-Vygotsky: The Social Genesis of Thought, eds. A. Tryphon \& J. Voneche, Psychology Press, Hove, pp. $145-155$.

Chi, M. \& Hausmann, R. (2003) 'Do radical discoveries require ontological shifts?' in International Handbook on Innovation, eds. L. Shavinina \& R. Sternberg, Elsevier Science Ltd, New York, pp. 430-444.

Cochrane, T. (2007) 'Moving mobile mainstream: using communities of practice to develop educational technology literacy in tertiary academics', in MLearn 2007 - Making the Connections 6th International Conference on Mobile Learning, eds. A. Norman \& J. Pearce, 16-19 October 2007 Melbourne Exhibition Centre, Melbourne, University of Melbourne, Parkville Victoria 3010, Australia, 37-45.

Cochrane, T. (2010) 'Beyond the yellow brick road: mobile web 2.0 informing a new institutional elearning strategy', Special Issue 'The Transformational Impact of Learning Technology' of ALT-J, Research in Learning Technology, vol. 18, pp. 221-231.

Cochrane, T., et al., (2012) 'Rethinking elearning support strategies', International Journal for Academic Development, iFirst October 19, pp. 1-18.

Cochrane, T. \& Kligyte, G. (2007) 'Dummies2Delight: using communities of practice to develop educational technology literacy in tertiary academics', in JISC Online Conference: Innovating eLearning, eds. G. Minshull \& J. Mole, 11-14 June 2007, JISC online conference, Direct Learn Services Ltd, The Limes, Norbury, Bishop's Castle, Shropshire, SY9 5EA, 36-38.

Engestrom, Y. (1987) Learning by Expanding: An Activity-Theoretical Approach to Developmental Research, Orienta-Konsultit, Helsinki.

Garnett, F. (2010) 'Heutagogy and the craft of teaching', Wordpress.com, [online] Available at: http://heutagogicarchive.wordpress.com/2010/11/18/heutagogy-the-craft-of-teaching/\#more340

Hase, S. \& Kenyon, C. (2000) 'From Andragogy to Heutagogy', ultiBASE Articles, [online] Available at: http://ultibase.rmit.edu.au/Articles/dec00/hase2.htm 
Head, G. \& Dakers, J. (2005) 'Verillon's trio and Wenger's community: learning in technology education', International Journal of Technology and Design Education, vol. 15, pp. 33-46.

Herrington, A. \& Herrington, J. (2007) Authentic mobile learning in higher education, Paper presented at the AARE 2007 International Educational Research Conference. Retrieved from http://researchrepository.murdoch.edu.au/5413/

Herrington, A., et al., (2006) 'The design of an online community of practice for beginning teachers', Contemporary Issues in Technology and Teacher Education, [online], 6 Available at: http://www.citejournal.org/vol6/iss1/general/article1.cfm

Herrington, J. \& Oliver, R. (2000) 'An instructional design framework for authentic learning environments', Educational Technology Research and Development, vol. 48, pp. 23-48.

Kukulska-Hulme, A. (2010) 'Mobile learning as a catalyst for change', Open Learning: The Journal of Open and Distance Learning, vol. 25, pp. 181-185.

Langelier, L. (2005) Working, Learning and Collaborating in a Network: Guide to the Implementation and Leadership of Intentional Communities of Practice, CEFIRO (Recherche et Études de cas collection), Quebec City.

Laurillard, D. (2001) Rethinking University Teaching: A Framework for the Effective Use of Educational Technology, Routledge, London.

Laurillard, D. (2012) Teaching as a Design Science: Building Pedagogical Patterns for Learning and Technology, Routledge, New York.

Lave, J. \& Wenger, E. (1991) Situated Learning: Legitimate Peripheral Participation, Cambridge, Cambridge University Press.

Luckin, R., Clark, W., Garnett, F., Whitworth, A., Akass, J., Cook, J., et al., (2010) 'Learnergenerated contexts: a framework to support the effective use of technology for learning', in Web 2.0-Based E-Learning: Applying Social Informatics for Tertiary Teaching, eds. M. Lee \& C. Mcloughlin, IGI Global, Hershey, PA, pp. 70-84.

McLoughlin, C. \& Lee, M. (2008) 'Mapping the digital terrain: New media and social software as catalysts for pedagogical change', in Proceedings of ASCILITE 2008, eds. A. Farley \& D. Holt, Deakin University, Melbourne, Australia, pp. 641-652.

McLoughlin, C. \& Lee, M. (2010) 'Pedagogy 2.0: critical challenges and responses to web 2.0 and social software in tertiary teaching', in Web 2.0-Based E-Learning: Applying Social Informatics for Tertiary Teaching, eds. M. Lee \& C. Mcloughlin, IGI Global, Hershey, PA, pp. 46-69.

Reeves, T., Herrington, J. \& Oliver, R. (2005) 'Design research: a socially responsible approach to instructional technology research in higher education', Journal of Computing in Higher Education, vol. 16, pp. 97-116.

Siemens, G. (2004) 'Connectivism: a learning theory for the digital age', eLearnspace, [online] Available at: http://www.elearnspace.org/Articles/connectivism.htm

Swantz, M. L. (2008) 'Participatory action research as practice', in The SAGE Handbook of Action Research: Participative Inquiry and Practice, eds. P. Reason \& H. Bradbury, 2nd edn, SAGE Publications, London, pp. 31-48.

Vygotsky, L. (1978) Mind in Society, Cambridge, MA, Harvard University Press.

Wadsworth, Y. (1998) 'What is participatory action research?' Action Research International, [online], 2002 Available at: http://www.scu.edu.au/schools/gcm/ar/ari/p-ywadsworth98. html

Wenger, E. (1998) Communities of Practice: Learning, Meaning, and Identity, Cambridge University Press, Cambridge.

Wenger, E. (2005) 'Communities of practice: a brief introduction'. [online] Available at: http:// www.ewenger.com/theory/index.htm

Wenger, E. (2006) 'Communities of practice: a brief introduction'. [online] Available at: http:// www.ewenger.com/theory/index.htm

Wenger, E., White, N. \& Smith, J. (2009) Digital Habitats: Stewarding Technology for Communities, CPsquare, Portland, OR.

Wenger, E., White, N., Smith, J., Rowe, K. (2005) 'Technology for Communities', in Working, Learning and Collaborating in a Network: Guide to the implementation and leadership of intentional communities of practice, ed. L. Langelier, CEFIRO, Quebec, pp. 71-94. 